\title{
Spousal Employment and Intra-Household Bargaining Power
}

\author{
Francisca M. Antman ${ }^{\star *}$ \\ University of Colorado Boulder
}

\begin{abstract}
This paper considers the relationship between work status and decision-making power of the head of household and his spouse. I use household fixed effects models to address the possibility that spousal work status maybe correlated with unobserved factors that also affect bargaining power within the home. Consistent with the hypothesis that greater economic resources yield greater bargaining power, I find that the spouse of the head of household is more likely to be involved in decisions when she has been employed. Similarly, the head of household is less likely to be the sole decision-maker when his spouse works.
\end{abstract}

\section{Keywords}

intra-household; bargaining power; decision-making; gender; family

A significant portion of the literature on intra-household allocations has been dedicated to testing the unitary model of household decision-making, that is, the theoretical assumption that the family can be treated as though it operates as a single decision-maker (Lundberg and Pollak 1994). Studies in this area are now often set in developing countries and estimate the effects of increasing women's relative economic resources within the household on variables such as expenditures or outcomes for children (Bobonis 2009; Duflo 2003; Thomas, 1994). The implied mechanism is that greater economic power yields greater bargaining power and thus allows individuals to steer allocations in their preferred direction. As long as the bargaining process is unobserved, however, a concrete link remains elusive. While evidence on these matters is now becoming available in the form of surveys on household decisionmaking (Morozumi 2011) and policy experiments making transfers to women in particular (Attanasio and Lechene 2002), little is known about the most prevalent channel by which women might increase their bargaining power-labor supply. This paper takes a first step toward closing that gap by investigating the relationship between spousal employment and explicit measures of intra-household decision-making power.

Specifically, I examine the relationship between work status of the spouse of the head of household and the likelihood that the head alone is responsible for decisions regarding major household expenditures as well as the likelihood that the spouse is involved in these decisions. Of course, estimation of a causal effect of the spouse's employment on her

\footnotetext{
* I am grateful to Terra McKinnish and Elizabeth Brainerd as well as participants at the 2012 AEA meetings for their feedback on the preliminary results. Any remaining errors are my own.

** Department of Economics, University of Colorado at Boulder. 256 UCB, Boulder, CO 80309. francisca.antman@ colorado.edu.
} 
influence over household decisions is riddled with potential endogeneity problems. Quite simply, families in which spouses have a greater say in household decision-making may also have a greater propensity for spousal employment due to some omitted variable. To address these issues, I exploit longitudinal data to present a household fixed effects strategy that purges the estimates of sources of endogeneity that are fixed over time within the household, such as attitudes toward women and work. The results are consistent with the hypothesis that increasing economic resources results in an increase in bargaining power. When spouses work outside the home, they are more likely to be involved in household decisions and the head is less likely to be the sole decision-maker.

\section{Data and Descriptive Statistics}

To explore these questions, I use data from the Mexican Family Life Survey (MXFLS), a two-wave representative panel survey which interviewed respondents once in 2002 and again around 2005-2007. ${ }^{1}$ The MXFLS collects detailed demographic, expenditure, and labor supply data for all members of the household. The survey is especially suited for this exercise in that it asks the head of household to identify who is responsible for making decisions regarding expenses and time allocation related to many aspects of household management. Here, I focus on decisions concerning large expenditures for the home (e.g. refrigerator, car, furniture) as a critical area of household decision-making that is arguably less likely to be plagued by gender-specific cultural norms.

Respondents can report that any combination of the following people is responsible for making the decisions in this area: the respondent himself, his spouse, children, mother, father, brother, sister, in-laws, and grandparents. Based on the head's responses, I construct variables which (1) indicate the head of household is reported to be solely responsible for the decision and (2) indicate that the spouse is one of the decision-makers involved. The latter includes cases in which she is the sole decision-maker as well as cases in which she makes decisions in conjunction with her partner and/or others.

Table 1 reports summary statistics on the sample of 9,551 household-period observations pooled over both waves of the survey. About 31 percent of household heads report that they alone make decisions regarding major household expenditures while 67 percent of household heads report that their spouses are involved in the decision. Virtually all households in the sample are headed by a man ( 97 percent), justifying the perception that the head of household is almost always male, and thus the spouse's employment is largely equivalent to female employment.

Table 1 also shows how these descriptive statistics differ in households where the spouse is reported to have worked in the last 12 months. This represents a significant distinction because while 88 percent of household heads worked in the last 12 months, only 24 percent (2254/9551) of their spouses worked over the same period. Consistent with the bargaining power hypothesis, heads of households in which the spouse worked are less likely to report that they are solely responsible for the decisions $(0.23$ versus 0.34$)$ and more likely to report

\footnotetext{
${ }^{1}$ Documentation and data are available at http://www.ennvih-mxfls.org/.
} 
that spouses are involved in making decisions ( 0.75 versus 0.63$)$. These households are also younger, more educated, and slightly less likely to be headed by a man, just as one would expect with changing cultural norms surrounding women's work and intra-household decision-making. This suggests that households that differ in terms of spousal employment may also differ in other (potentially unobserved) ways that may be correlated with both the decision-making environment and the likelihood that the spouse works. To the extent that these factors are likely to be fixed over time, this motivates the use of the household fixed effect strategy used in estimation.

\section{Empirical Strategy}

To assess the relationship between the spouse's work status and household decision-making, I estimate the following regression model:

$$
\text { WhoMakesDecision }_{i t}=\beta_{1} \text { Spouse }_{\text {Worked }_{i t}}+\beta_{2} \text { Head }_{\text {Worked }}+\mathbf{X}_{\mathrm{it}} \gamma+u_{i}+\varepsilon_{i t} \text {. }
$$

where WhoMakesDecision ${ }_{i t}$ is a variable indicating who is involved in making the decision regarding big home expenditures. In the first model it is equal to one if the head is reported to make decisions alone regarding large home expenditures and zero otherwise, and in the second case it takes the form of a dummy variable equal to one if the spouse is reported to be involved in making decisions regarding large home expenditures and zero otherwise. SpouseWorked $_{i t}$ is a dummy variable indicating whether the spouse is reported to have worked or developed any activity to help with household expenditures during the last 12 months. HeadWorked ${ }_{i t}$ is the analogous variable describing the work status of the head of household. The vector of covariates, $\mathbf{X}_{\mathrm{it}}$, includes demographic controls for the household (number of household members that are males $0-5,6-17,18-64$, and 65 or over, as well as number of household members in the analogous female age categories), and dummy variables for year in the second wave of the survey. All time-invariant observable and unobservable household characteristics are captured by the household fixed effect, $u_{i}$.

\section{Results}

Table 2 reports the results from estimation of equation (1), interpreted as a linear probability model. ${ }^{2}$ For comparison, columns 1 and 2 report the results without including the household fixed effects, and thus vulnerable to the critique that unobserved differences between households in which the spouse was employed and those in which she was not are actually driving differences in decision-making power. Columns 1 and 2 show that the spouse's employment is associated with a 10.6 percentage point drop in the likelihood that the head of household makes the decision alone regarding large household expenditures, and an increase in the likelihood that the spouse is involved in household decisions of about the same magnitude (point estimate of 0.119).

\footnotetext{
${ }^{2}$ Arguably, a bivariate probit model with fixed effects would better account for the binary nature of the dependent variable and independent variable of interest. However, due to the large number of household fixed effects, estimation is computationally difficult. Results from logit and conditional logit estimation are qualitatively similar to those reported here.
} 
After including household fixed effects, the magnitudes of these estimates drops somewhat, but the pattern of results remains the same. Column 3 shows that the spouse's employment is associated with a five percentage point drop in the likelihood that the head alone makes decisions and column 4 shows an increase in the likelihood that spouses are involved in these decisions of about the same magnitude. Given that about 30 percent of households report that the head is solely responsible for the decision and roughly 60 percent of households report that the spouse is involved in the decision (Table 1), these results suggest that spousal work status has a relatively larger impact on the likelihood that the head makes unilateral decisions. Nonetheless, it makes sense that the magnitudes of the estimates are very close, suggesting that a drop in the head's decision-making power coincides with an increase in his spouse's decision-making power.

\section{Conclusion}

The literature on intra-household allocations often links economic power of household members with allocations, expenditures, or outcomes, hypothesizing that those with greater economic power will have greater bargaining power and thus steer the allocation in their preferred direction. ${ }^{3}$ The missing link in this chain of causation, however, is the typically unobserved decision-making process within the household. This paper takes a first step toward closing that gap by examining household decision-making data and connecting it with the most widely available means of affecting relative economic resources within the household - spousal employment. Consistent with the bargaining power hypothesis, the evidence presented here points to a positive link between work status and household decision-making power and thus suggests that increasing economic opportunities for women may indeed have far-reaching consequences within the home.

\section{References}

Antman, Francisca M. International Migration and Gender Discrimination among Children Left Behind. American Economic Review. 2011; 101(3):645-49. [PubMed: 23239896]

Attanasio, Orazio; Lechene, Valerie. Tests of Income Pooling in Household Decisions. Review of Economic Dynamics. 2002; 5:720-748.

Bobonis, Gustavo. Is the Allocation of Resources within the Household Efficient? New Evidence from a Randomized Experiment. Journal of Political Economy. 2009; 117(3):453-503.

Duflo, Esther. Grandmothers and Granddaughters: Old-Age Pensions and Intrahousehold Allocation in South Africa. The World Bank Economic Review. 2003; 17(1):1-25.

Lundberg, Shelly; Pollak, Robert A. Noncooperative Bargaining Models of Marriage. The American Economic Review. 84(2):132-137.

Morozumi, Ryoko. A Test of a Unitary Model on Labor Supply Using Data on Household DecisionMaking Systems. Applied Economics. 44(33):4291-4300.

Thomas, Duncan. Like Father, Like Son; Like Mother, Like Daughter: Parental Resources and Child Height. The Journal of Human Resources. 1994; 29(4):950-988.

\footnotetext{
${ }^{3}$ In this vein, Antman (2011) explores the impact of international migration of the head of household on expenditures within the home.
} 


\section{Table 1}

\section{Descriptive Statistics by Spousal Work Status}

\begin{tabular}{lccc} 
& & \multicolumn{3}{c}{ Spouse worked last 12 months } \\
& Full Sample & No & Yes \\
\hline Head alone makes decision regarding big home expenditures & $0.31(0.46)$ & $0.34(0.47)$ & $0.23(0.42)^{+}$ \\
Spouse is involved in making decision regarding big home expenditures & $0.67(0.47)$ & $0.63(0.48)$ & $0.75(0.43)^{+}$ \\
Head worked last 12 months & $0.88(0.33)$ & $0.87(0.34)$ & $0.90(0.31)^{+}$ \\
Head's education (years) & $6.41(4.32)$ & $5.91(4.15)$ & $7.79(4.48))^{+}$ \\
Spouse's education (years) & $6.04(4.04)$ & $5.45(3.76)$ & $7.65(4.33))^{+}$ \\
Head's age & $46.19(14.86)$ & $47.30(15.58)$ & $43.14(12.14)^{+}$ \\
Spouse's age & $42.80(14.14)$ & $43.71(14.98)$ & $40.31(11.15)^{+}$ \\
Head is male & $0.97(0.17)$ & $0.99(0.08)$ & $0.91(0.28)^{+}$ \\
Household Size & $4.59(1.93)$ & $4.60(1.96)$ & $4.56(1.84)$ \\
Number of Observations & 9551 & 6997 & 2554 \\
\hline
\end{tabular}

Standard deviations in parentheses below point estimates

${ }^{+}$Difference in means is statistically significant, $\mathrm{p}<0.01$ 


\section{Table 2}

Household Decision-Making and Spousal Work Status

$\underline{\text { OLS and Fixed Effects Regression Results, Linear Probability Model }}$

(1)

(2)

(3)

(4)

Dep. var. indicates who makes decisions regarding big home

Head alone

Spouse involved

Head alone

Spouse involved expenditures

$-0.106(0.010)^{* * *} 0.119(0.010)^{* * *}-0.050(0.023)^{* *} 0.047(0.024)^{* *}$

Head worked in last 12 months

$0.072(0.015)^{* * *}$

$-0.023(0.016)$

$0.019(0.032)$

$-0.001(0.034)$

Household Fixed Effects

NO

NO

YES

YES

Observations

9551

9551

9551

9551

Robust standard errors in parentheses,

p $<0.1$;

** $<<0.05$

$* * *$

$\mathrm{p}<0.01$

Additional controls: number of household members in gender-age groups and indicators for year of second wave of survey 